\title{
VERBRUIKERSGEDRAG IN DIE SA WEERMAG : 'N ALTERNATIEWE SIENING
}

\author{
Deur Kapt J.A. Beukes*
}

\section{INLEIDING}

Omstandighede in die wêreld verander feitlik oornag. Kommunisme faal in OosEuropa, die oorlog in Angola is verby, Namibië verkry onafhanklikheid, die ANC word ontban en die Apartheidswette word afgeskaf. Hierdie gebeure was twee jaar gelede ondenkbaar. Die gevolge van bogenoemde gebeure het ook die Verdedigingsgemeenskap beïnvloed. Die Weermagbegroting is met meer as 3 miljard rand besnoei, diensplig is verkort, grootskaalse rasionalisasie word tans in die Weermag onderneem en in die algemeen heers daar groter finansiële dissipline in die SAW. Elke rand uitgegee moet behoorlik verreken en motiveer word. En veral na die BSB-debakel word SAW bedrywighede en besteding met valk-oë dopgehou. Dit is teen hierdie agtergrond dat verbruikersgedrag in die SA Weermag bespreek gaan word.

\section{BESTEK}

Aanvanklik word ' $n$ kort omskrywing van verbruikersgedrag gegee, waarna enkele verwante konsepte hanteer word. Die "uniekheid" van die Weermag, die feit dat die Suid-Afrikaanse Weermag terselfde tyd verbruiker en verbruikte is en net soos enige organisasie in ' $n$ bepaalde omgewing funksioneer, word geillustreer. Die bespreking word verder gevoer deur die verbruikerbesluitnemingsproses van toepassing te maak op die Weermag. Identifiseerbare fases is behoefteherkenning, die soektog na informasie, die evaluasie van alternatiewe, koopgedrag en uiteindelik ' $n$ uitkoms wat die organisasie tevrede of ontevrede laat. Hierdie basiese besluitnemingsproses word deur verskeie faktore beïnvloed wat in die verloop van die bespreking meer duidelik sal blyk.

\section{WAT IS .VERBRUIKERSGEDRAG?}

Verbruikersgedrag is die studie van WAT 'n verbruiker koop, WANNEER gekoop word, HOE gekOop word, HOEKOM gekOop word, WAAR gekoop word en HOE GEREELD die koopaksie geskied. Dié term behels dus daardie gedrag wat verbruikers openbaar in die soek, koop, gebruik, evaluering en wegdoening van produkte, dienste en idees wat hulle verwag hulle behoeftes sal bevredig (Schiffman en Kanuk, 1987, p6).

\section{VERWANTE KONSEPTE}

Verskeie verwante konsepte word dikwels deur Jan en alleman los en vas gebruik. Duidelikheidshalwe word die belangrikste terminologie kortliks bespreek (Schiffman en Kanuk, 1987) :

Persoonlike verbrulker. Die individu wat goedere en dienste koop vir ele gebruik (bv klere, motor ens).

Organisatoriese verbruiker. Hierdie kategorie verbruiker sluit besighede, staatsdepartemente en institusies (skole, kerke ens) in, wat produkte, dienste en toerusting aankoop sodat die organisasies vlot kan funksioneer (die tipe organisasies kan winsgewend of dienslewerend van aard wees).

Kopers en gebruikers. Die persoon wat die werklike aankoop doen is nie altyd die gebruiker nie. Net so is die koper nie noodwendig die persoon wat die produkbesluit of koopbesluit geneem het nie.

Verbruikerisme. 'n Organisasie wat deur verbruikers gestig is met die oogmerk om billike en etiese praktyke teenoor die verbruiker deur vervaardigers en handelaars te verseker.

\section{DOELWITTE IN ORGANISASIES}

Volgens Marx en Churr (1984, p84) is die hoofdoel van ' $n$ onderneming winsgewendheid en diens aan die gemeenskap. As winsgewendheid die swaarste weeg beteken dit dat die onderneming sy eie belang en veral dié van sy eienaars nastreef. As gemeenskapsdiens die hoofprioriteit is, sien die onderneming toe dat goedere en dienste beskikbaar gestel word wat die behoeftes van die gemeenskap kan bevredig en hulle welvaart kan bevorder. Hierdie twee aspekte hou ten nouste met 
mekaar verband. Newedoelwitte spruit voort uit die belange van die onderneming self en tweedens uit die belange van die gemeenskap. Die verwesenliking van newedoelwitte is slegs moontlik indien daarin geslaag word om die hoofdoel te bereik.

Doelwitte is noodsaaklik vir elke organisasie omdat dit ' $n$ eindresultaat, mikpunt of toestand is wat begeer word. Doelwitte verteenwoordig die oogmerke van die onderneming se bestaan, die rede vir totstandkoming, dit bepaal die organisasiestruktuur, die produkte, dienste en kliënte en is laastens noodsaaklik vir die organisasie se voortbestaan (Marx en Churr, 1984).

Die Suid-Afrikaanse Weermag, as 'n outonome staatsdepartement, vorm deel van die staat se meganisme om die land te bestuur in samewerking met ander staatsdepartemente. As 'n organisatoriese verbruiker kan die Weermag beskou word as beide ' $n$ verbruiker en verbruikte ("verbruiksartikel"). As verbruiker word mense, goedere, dienste, tegnologie, wapens en finansies gebruik ten einde doelwitte te bereik. As verbruikte word die SAW deur die regering, gemeenskap en land gebruik ten einde sekere doelwitte te verwesenlik. Doelwitte van die SAW spruit voort uit die Verdedigingswet, Wet no 44/57 (soos gewysig) en behels die volgende :

\section{Diens ter verdediging van die RSA.}

\section{Diens ter voorkoming of onderdrukking} van terrorisme.

Diens ter voorkoming of onderdrukking van binnelandse onluste.

Diens ter behoud of bewaring van lewens, gesondheid of eiendom of ter instandhouding van noodsaaklike dienste.

Polisiedienste soos voorgeskryf.

Doelwitte van die Weermag is in ooreenstemming met die oorhoofse politieke doelwitte van die regering solank dit al die inwoners tot voordeel strek, en nie vir partypolitieke gewin is nie. Die Weermag moet dus 'n klimaat help skep vir die land se inwoners om in te leef en te werk. Soos reeds gesien beïnvloed gebeure die doelwitte en werksaamhede in die SAW. Dit gebeur omdat die Weermag nie in ' $n$ vakuum funksioneer nie, maar binne 'n bepaalde sosio-tegniese sisteem. (Om al die kragte wat op doelwitte in werk te illustreer, sien diagram 1.)
Diagram 1 : Die Sosio-tegniese sisteem.

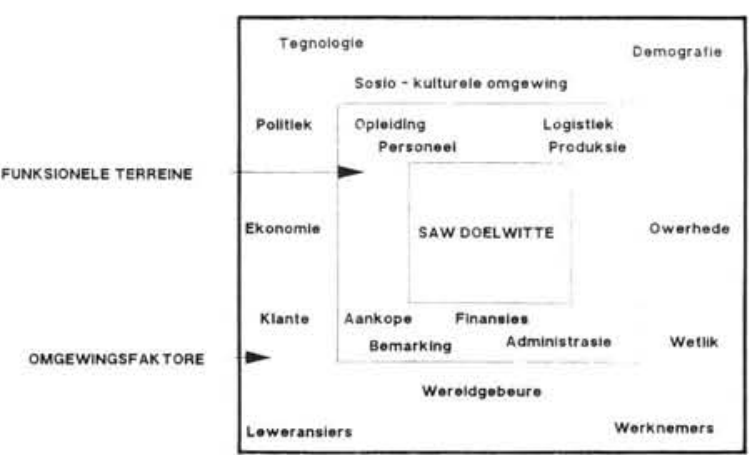

(Aangepas uit Marx en Churr, 1984)

Twee vlakke is van belang, $\mathrm{nl}$ ' $\mathrm{n}$ mikroomgewing en 'n makro-omgewing. Daar is egter ' $n$ voortdurende wisselwerking tussen die twee vlakke wat SAW doelwitte direk of indirek beïnvloed. In die nastrewing van doelwitte kan verbruikersgedrag ' $n$ prominente rol speel. Dikwels word verbruikersgedrag beskou as dit wat tuishoort by bemarkingsorganisasies. Die Amerikaanse Leer het deur voortreflike verbruikersnavorsing en die korrekte verstandhouding tov verbruikersmotiewe en -gedrag, 'n bekwame mag van vrywilligers daargestel. Na die Watergate en Viëtnam era het die Amerikaanse leër groter sukses behaal met hulle bemarkingsveldtog ten spyte van die negatiewe beeld wat in daardie stadium aan die verdedingingsmagte gekleef het. Dit was hoofsaaklik te danke aan hulle bemarkingsveldtog met die sentrale tema: "Today's Army Wants to Join You". Diens in die Leër is voorgestel as ' $n$ normale en noodsaaklike stap tussen hoërskool en volwassenheid - en nie net iets wat nodig is in oorlogstyd nie. Hierdie tema het in die 80 's drasties verander agv veranderde omstandighede. Die nuwe tema lui: "Army $\mathrm{Be}$ All You Can Be". Dit reflekteer 'n verskuiwing vanaf basiese motivering na prestasie en die handhawing van ' $n$ sinvolle lewe (Engel, Blackwell en Miniard, 1987).

Die vraag is of verbruikersgedrag ook in die Suid-Afrikaanse Weermag ' $n$ bydrae kan lewer tot doelwitbereiking. Ten einde hierdie vraag te beantwoord is dit nodig om die organisatoriese verbruikersbesluitnemingsproses in weermagverband van nader te ondersoek. Die bespreking sal gevoer word aan die hand van ' $n$ model daargestel deur Engel, Blackwell en Miniard (1987, p 35). 


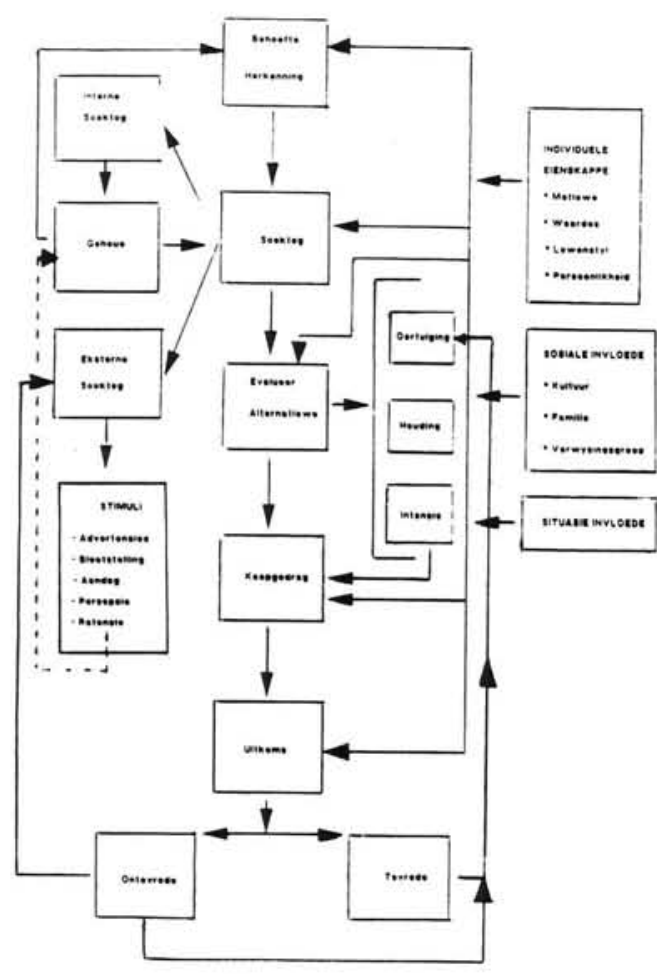

(Nereenvoudigde verbrulkersbes/uitnemingsmodel van Engel, Blackwell en Miniard)

\section{DIE VERBRUIKERBESLUITNE- MINGSPROSES}

\section{BEHOEFTEHERKENNING (PROBLEEMHERKENNING)}

As verbruiksartikel word die SAW aangewend deur bv die owerheid en die gemeenskap sodra 'n bepaalde behoefte ontstaan. Voorbeelde hiervan is wanneer die kabinet besluit om vir strategiese of veiligheidsredes basisse in buurlande aan te val of grootskaalse operasies in Angola te loods. Die oorstromings in Natal is ' $n$ voorbeeld van hoe die SAW hulp verleen het aan die gemeenskap, alhoewel die bevel op topbestuursvlak gegee is. In so 'n geval verwag die gemeenskap dat die SAW sal optree en 'n diens lewer. Wat in kort dus hier gebeur het, is dat ' $h$ gaping/ leemte tussen die begeerde en werklike stand van sake geïdentifiseer is. Itv doelwitstelling, is dit ' $n$ doelwit waarna gestreef moet word, $\mathrm{nl}$ ' $\mathrm{n}$ stabiele land waarbinne die gemeenskap kan funksioneer. As verbruiker kom die Weermag ook met probleemherkenning in aanraking. Voorbeelde is : Hoof van Staf Operasies en sy personeel besef dat die inligting beskikbaar onvoldoende is om ' $n$ operasie te loods; of dat huidige magsterkte op die SA noordgrens te klein is en dat versterkings en toerusting daarheen gestuur moet word; of dat helikopters en personeel van ander gebiede onttrek moet word om te help met redddingspogings in Natal. 'n
Meer aktuele voorbeeld is die veldtog wat tans gevoer word om diensplig af te skaf. Op die oomblik wil dit voorkom asof dit slegs 'n klein persentasie van die totale mark (gemeenskap) is, wat die verandering wil sien. Sou so 'n gedagte egter groot steun vanuit die gemeenskap verkry, sal besluitnemers ' $n$ ander stelsel moet oorweeg met inagneming van die potensiële bedreiging. Per slot van sake is die Weermag uit die gemeenskap, vir die gemeenskap (verbruikte en verbruiker). Probleemherkenning/-behoefteïdentifisering word op beide vlakke beïnvloed deur ' $n$ hele aantal faktore. Enkeles word aangehaal :

Ekonomlese omgewing : Plaaslike, nasionale of internasionale tendense kan 'n groot invloed uitoefen. Op 'n mikrovlak kan die arbeidsomsetkoers of 'n grootskaalse ondersoek na wanbesteding van fondse in die SAW moontlik verhoed dat die SAW betrokke raak in enige konflik. Op makrovlak kan betalingsbalansprobleme, grootskaalse buitelandse skuldterugbetalings asook veranderings in die goud en olieprys ' $n$ invloed uitoefen op die owerheid se uiteindelike besluit. Dit moet egter beklemtoon word dat as 'n operasie van strategiese belang sou wees, of as dit ' $n$ uiters dringende saak is, sal die sentrale regering, die gemeenskap en die SAW nie skroom om op te tree nie ten spyte van die gevolge ( $B \vee$ aardbewings, inval uit die noorde ens).

Politiek : Die politieke klimaat in 'n land is 'n belangrike faktor aangesien dit al die ander faktore wat 'n ekonomiese stelsel uitmaak, beïnvloed. Die politieke stabiliteit, ideologieë en doelwitte van die regerende party raak die SAW direk sowel as indirek, maar die Staat is die rigtingewende faktor. Werklike en potensiële aanslae op ' $n$ land en sy vermoë om homself te verdedig het ' $n$ belangrike invloed op die bedryflewe van 'n land. Die feit dat ' $n$ omvattende aanslag teen die RSA op militêre, ekonomiese en kulturele gebied gevoer is, is ' $n$ bewys van die land se strategiese belang vir die Weste en Ooste. Die SAW as verbruikte, sowel as verbruiker word direk beïnvloed deur politieke veranderinge, omrede die SAW een van die instrumente is vir die uitvoering van die regering se aktiwiteite onder stabiele toestande. Hierdeur word die aktiwiteit van regering vergemaklik.

Sosiale omgewing : Omdat die SAW mense in diens neem en ' $n$ diens aan die gemeenskap lewer, bevind die SAW as 
verbruiker homself binne ' $n$ sosiale omgewing en moet daar gekyk word na die sosiale klimaat soos geopenbaar deur waardestelsels, ideologië, houdings, kultuur, familie invloede, die rol van verwysingsgroepe, sosiale stratifikasie en etniese invloede. So kan negativisme, die verspreiding van gerugte en klagtes van die publiek en ouers uiteindelik ' $n$ groot invloed uitoefen op SAW besluitneming. Die rede? Die Weermag het ' $n$ bepaalde beeld om uit te dra. As verbruikte word besluitneming in die SAW indirek geraak deur die beïnvloeding van die regering/gemeenskap deur globale wêreldneigings en spesifieke gebeure soos 'n onafhanklike Namibië en die demokratisering van Oosbloklande.

Die konkurrende omgewing : As staatsdepartement bestaan die SAW se konkurrende omgewing nie slegs uit ander departemente wat om die belastingbetaler se geld meeding nie. Mededinging bestaan ook tov alle insette, dws alles wat hy mag nodig hê om sy doelwitte te bereik itv mannekrag, toerusting, voertuie, kapitaal, voorrade, geboue, die vyand, ens. As verbruiksartikel van die owerheid word besluitneming ook beïnvloed deurdat die owerheid op staatkundige, politieke en ekonomiese terreine meeding met ander moonthede.

Tegnologiese omgewing : Besluitneming in die SAW (veral op strategiese vlak) word baie sterk deur tegnologie beïnvloed. Nuwe of verdere ontwikkelings op die gebied van rekenaars, missiele, elektronika en artilleriestelsels het daartoe bygedra dat die SA Magte in Angola groot welslae behaal het. Die feit dat Krygkor "gereeld" nuwe wapenstelsels bekend stel, dra daartoe by dat die beeld van paraatheid, die "sterkmansbeeld" die publiek bybly.

\section{SOEKTOG}

Sodra ' $n$ bepaalde behoefte geïdentifiseer is, moet tot aksie oorgegaan word. Die eerste stap is om te bepaal of voldoende inligting beskikbaar is oor 'n bepaalde onderwerp (interne soektog). Op individuele vlak beteken interne soektog dat informasie vanuit die geheue herroep word. Op organisatoriese vlak word dit deur verskeie individue gedoen, en twee addisionele bronne van informasie is hier van belang, $\mathrm{nl}$ ondervinding (lesse geleer) en informasie opgegaar (bv op rekenaar, in liaseerstelsels, lêers ens). Sou interne bronne van informasie onvoldoende blyk te wees, moet oorgegaan word na die eksterne soektog. So word insamelaars (vanuit SAW oogpunt) uitgestuur om die relevante inligting te kry. Informasie kan ook verkry word deur met kundiges te gesels, ander inligtingsdienste te kontak en soms ook die radio, televisie, algemene media en marknavorsing te gebruik. Hoe die SAW as verbruiker en verbruikte die soektog sal aanpak sal afhang van die mate van betrokkenheid (strategiese belang en risiko), beskikbaarheid van informasie en koste van die soektog. Een van die belangrikste eksterne bronne van informasie is marknavorsing.

Marknavorsing. Indien interne bronne nie bevredigende resultate oplewer nie, kan marknavorsing as deel van die eksterne soektog na alternatiewe/informasie aangepak word. Die Weermag as organisasie (verbruiker) het die Militêre Psigologiese Instituut tot sy beskikking om behulpsaam te wees met sodanige navorsing. Sekere kommandemente het ook navorsing en ontwikkelingafdelings wat betrek kan word. Die owerheid kan hom wend tot die RGN of WNNR of ander organisasies afhangend van die tipe probleem wat ervaar word. Met marknavorsing is dit belangrik om die verbruiker se regte en behoeftes te verstaan. Die Weermag as verbruiker van mense moet hulle regte tot veiligheid, tot informasie, vrye keuses en om aangehoor word, erken en op die hart dra. Net so moet die owerheid ook bg regte in ag neem tov die Weermag as entiteit. Aspekte wat bv troepe direk raak moet met groot sorg hanteer word. Opleiding van troepe geskied ooreenkomstig uiters streng veiligheidstandaarde (reg tot veiligheid); bevelsinformasieperiodes word weekliks gebruik om troepe in te lig aangaande gebeure in die SAW/ RSA (reg tot informasie); dienspligtiges kan kies in watter weermagsdeel wil hulle hul diensplig verrig en selfs in watter peleton en saam met watter vriende (reg tot vrye keuse); en laastens het troepe/dienspligtiges ' $n$ inset op die eenheidskomitee waar griewe gelig kan word teenoor die bevelvoerder (reg om aangehoor te word).

Met die loodsing van nuwe produkte (bv wapenstelsels) is dit krities om die hele proses te bestuur, omrede groot bedrae geld, tegnologiese en ander bronne verbruik word in die vervaardigingsproses. Vanuit ' $n$ owerheids- en gemeenskapsoogpunt (waar die SAW die verbruiksartikel is) kan die dienspligstelsel as 'n nuwe produk beskou word (innovasie). Die 
verkorte dienspligstelsel het volle mediadekking geniet. Die implikasies van die aankondiging is nuwe verwantskappe wat nie net die Weermag se mannekragsituasie direk geraak het nie, maar ook verreikende ekonomiese implikasies kan hê. Verdere bemarkingsimplikasies vir beide verbruiker (owerheid/gemeenskap) en verbruikte (SAW) is :

Monitor algehele tevredenheld tov die nuwe stelsel. Afwesigheid van klagtes is nie noodwendig ' $n$ teken van tevredenheid nie.

Neem klagtes ernstig op. Binne die SAW kan dit baie demoraliserend inwerk en vinnig soos ' $n$ vrot kol versprei. Ook die owerheid moet bereid wees om klagtes van die SAW (as entiteit) aan te hoor en te ondersoek.

Realistiese verwagtinge moet gehandhaaf word. Hierdie aspek het veral dienspligtiges geraak wat reeds in die stelsel was en minder "afslag" gekry het. Die beginsel van hou jou ondergeskiktes ingelig, moet toegepas word.

Klem word nou geplaas op kwalitelt van opleiding en nie kwantiteit nie.

$\mathrm{Na}$ implementering is versterking nodig, daarom is terugvoer tov die stelsel se "prestasie" van groot belang. Die houding van die gemeenskap teenoor die dienspligstel sal streng gemonitor moet word.

\section{DIE EVALUASIE VAN ALTERNATIEWE}

Nadat voldoende informasie ingesamel is (intern, sowel as ekstern), moet die verskillende alternatiewe geëvalueer word. Meer kriteria sal gebruik word as dit 'n komplekse probleemoplossingsproses is, in teenstelling met roetine besluite. As verbruiksartikel kan die owerheid/gemeenskap kriteria soos reputasie van die SAW, relatiewe belangrikheid van 'n alternatief, effektiwiteit en welvaart van die land gebruik om die SAW te mobiliseer om tot ' $n$ bepaalde aksie oor te gaan. Die SAW as verbruiker kan dieselfde kriteria gebruik, maar omdat die SAW nie net ' $n$ verbruiker van produkte nie, maar ook van mense is, word kriteria dikwels gebruik wat in ooreenstemming is met personeel se onderliggende motiewe. Die evaluering van alternatiewe word beïnvloed deur 3 konsepte $\mathrm{nl}$ oortuigings, houdings en voornemes (intensies) :
Oortulging: Vanuit owerheidsoogpunt het die Weermag as 'n verbruiksartikel 'n bepaalde beeld. Hierdie beeld beïnvloed moontlike optrede of besluitneming aan owerheidskant. ' $n$ Voorbeeld hiervan is die ondersoek na die BSB wat die beeld van die Weermag skade berokken het. Die Weermag se reaksie na buite was dat volle samewerking gegee sal word met die ondersoek (die kwessie van eerlikheid en geloofwaardheid tree hier na vore). Die Minister van Verdediging het voorts in die parlement verklaar dat alle vrot kolle uitgesny sal word, al beteken dit ook dat baie diep gesny sal word.

Houding : Voortspruitend uit oortuiging ("belief") wat hoofsaaklik bepaal word deur produkbeeld is die kwessie van houdings. Houding word direk beïnvloed deur persepsie en die verbruiker beoordeel alternatiewe op grond van sy persepsie. Deur die SAW se beeld te verander word gepoog om ook ' $n$ meer positiewe houding teenoor die SAW te kweek. ' $n$ Voorbeeld hiervan is $n$ wapendemonstrasie wat in 1990 vir parlementslede by Tooth Rock (aan die Weskus) gehou is. Die direkte uitvloeisel hiervan was moontlik die positiewe houding wat in die parlement geopenbaar is jeens die Weermag tydens die Verdedigingsbegrotingsdebat omdat die lede nou geweet het waaroor dit gaan. Dit was nie nou net nog syfers op papier nie, maar werklike ervaring van die realiteit van 'n parate Weermag wat ter sprake was.

Voornemes : 'n Positiewe houding tov 'n alternatief lei tot 'n voorneme om 'n bepaalde alternatief te kies. Voorneme (intensie) is die direkte voorloper tot werklike koopgedrag. Of koopgedrag werklik sal plaasvind sal grootliks afhang van die sterkte van die intensie - gedragverwantskap wat op die volgende wyses beïnvloed kan word :

i. Hoe korter die tydsinterval voor koopgedrag hoe sterker is die verwantskap.

ii. Houdings (en intensies) wat gebasseer is op ondervinding sal waarskynlik meer in ooreenstemming wees met gedrag as wanneer indirekte ondervinding ter sprake is. ' $n$ Hele aanvalsmag het byvoorbeeld weke lank ingeoefen vir die operasie en net voordat die mag tot optrede kon oorgaan is die operasie tydelik gehalt vanweë ' $n$ informasiebreuk en onverwagte vyandelike bewegings wat die operasie 
kon beïnvloed. Wat dus in effek gebeur het, was voordat besluit is op ' $n$ bepaalde alternatief (intensie) deur die kabinet/ topbestuur, het 'n relatief lang tydperk verloop voordat tot aksie oorgegaan kon word. Alhoewel die intensie - gedragverwantskap sterk was, het tydsverloop 'n definitiewe invloed op die verwantskap gehad omdat soveel eksterne faktore 'n rol kan speel. Dus, vanuit beide oogpunte van verbruiker en verbruikte (SAW) is dit belangrik om tydverloop te minimaliseer ten einde die intensie - gedragverwantskap so sterk moontlik te hou.

\section{KOOPGEDRAG}

"Koopgedrag" volg direk op die intensie om te koop. Die "koopproses" bevat besluite oor hoe om te koop en waar om te koop. Uit 'n organisasie oogpunt is koopgedrag baie meer kompleks vanweë die feit dat meer persone betrokke is, doelwitte van verskeie individue en die organisasie in ag geneem moet word, die risiko van 'n verkeerde besluit groter is en die interafhanklikheid tussen verskaffers en koper ' $n$ rol speel. (LW in hierdie konteks kan die woord koopgedrag vervang word deur "aksie, optrede en uitvoering"). Die Weermag as verbruiksartikel van die regering moes onttrek vanuit SWA omrede dit by die groter plan van die regering ingepas het. Suidwes kon onafhanklik word en die Kubane het begin met ' $n$ onttrekkingspoging vanuit Angola. Word hierdie aksie itv uitkomste evalueer, blyk dit baie positief te wees, alhoewel dit slegs ' $n$ klein skakel in 'n groter geheel vorm. As verbruiker van mense blyk die uitkoms van bg aksie soos volg te wees:

Voordele (tevredenheid)

i. 'n Kleiner verdedigingsbegroting stel meer geld beskikbaar vir meer noodsaaklike dienste.

ii. Meer personeel is beskikbaar vir poste (beter posbenutting).

iii. ' $n$ Verkorte dienspligstelsel (kleiner effek op die SA ekonomie)

\section{Nadele (ontevredenheid)}

i. Die "vyand" is in Namibië aan bewind ten spyte van Weermag welslae op die slagveld.

ii. In sekere Weermagsdele is personeel botallig (meer personeel in verhouding tot aantal poste beskikbaar).
Tevredenheid tov ' $n$ bepaalde uitkoms lei daartoe dat die oortuiging/houding wat oor ' $n$ bepaalde alternatief/produk/aksie bestaan versterk word. Ontevredenheid daarenteen sal lei tot verdere eksterne soektog.

\section{SLOTSOM}

Alhoewel hierdie bespreking ' $n$ ander inslag het as dit wat die privaatverbruiker en privaatonderneming dikwels ervaar, is die onderliggende beginsels (tov bemarking, advertering en gedrag) steeds dieselfde. Die tweeledige karakter van die Weermag, dws die feit dat hy terselfdertyd verbruiker en verbruikte is, verleen 'n nuwe dimensie aan verbruikersgedrag. Die beeld van die Suid-Afrikaanse Weermag en die persepsie wat by landsburgers heers, sal in die toekoms streng gemonitor moet word. Daar bestaan geen twyfel nie dat verbruikersgedrag in so ' $n$ dinamiese omgewing dieselfde vir die SAW kan beteken as wat dit vir die Amerikaanse Leër beteken het.

\section{*Kapt J.A. Beukes is 'n dosent in Bedryfs- sielkunde aan die Fakultelt Krygskunde, Universiteit van Stellenbosch.}

\section{BIBLIOGRAFIE}

\author{
1. Engel, J.F.; Blackwell, R.D. en Miniard, P.W. (1986) \\ Consumer Behavior. Sth edition. New York : CBS.
}

2. Lucas, G.H.G; De Coning, C.; Marx, S. en Oosthuizen, H. (reds) (1981) Die Taak van die Bemarkingsbestuur. Pretoria : Van Schaik.

3. Marx, F.W. en Churr, E.G. (1984) Grondbeginsels van die Bedryfsekonomie, Hersiene Uitgawe. Pretoria : Haum.

4. Schiffman, L.G. en Konuk, L.L. (1987) Consumer Behavior, 3rd edition. London : Prentice-Hall.

5. Verdedigingswet, Wet no 44/57 (soos gewysig). 